Article

\title{
An Exploratory, Cluster Randomised Control Trial of the PAX Good Behaviour Game
}

\author{
Joanne O'Keeffe ${ }^{1, *}$, Allen Thurston ${ }^{1}$, Frank Kee ${ }^{2}$, Liam O'Hare ${ }^{1}$ and Katrina Lloyd ${ }^{1}$ \\ ${ }^{1}$ School of Social Sciences, Education and Social Work, Queen's University Belfast, UK; E-Mails: j.okeeffe@qub.ac.uk (J.O.K.), \\ a.thurston@qub.ac.uk (A.T.), I.ohare@qub.ac.uk (L.O.H.), k.lloyd@qub.ac.uk (K.L.) \\ ${ }^{2}$ Centre for Public Health, Queen's University Belfast, UK; E-Mail: f.kee@qub.ac.uk (F.K.) \\ * Corresponding author
}

Submitted: 13 June 2021 | Accepted: 2 August 2021 | Published: 13 October 2021

\begin{abstract}
This article presents the findings of an exploratory randomised controlled trial of the PAX Good Behaviour Game (PAX GBG) in Northern Ireland. The PAX GBG is an evidence-based universal prevention programme designed to improve mental health by increasing self-regulation, academic engagement, and decreasing disruptive behaviour in children. The study was designed in line with the Medical Research Council guidance on the development of complex interventions and is based on the Medical Research Council framework, more specifically within a Phase 2 exploratory trial. The study used a cluster randomised controlled trial design with a total of 15 schools (19 classes) randomised to intervention and control. This article reports specifically on the outcome of self-regulation with 355 elementary school pupils in year 3 (age $M=7.40$, $\mathrm{SD}=0.30$ ). Participating schools in the trial were located in areas of socio-economic disadvantage. The teachers in the intervention group received training in the delivery of the PAX GBG and implemented the PAX GBG intervention for 12 weeks. A range of pre- and post-test measures, including child reported behaviours, were undertaken. After the 12 weeks of implementation, this exploratory trial provided some evidence that the PAX GBG may help improve self-regulation $(d=.42)$ in participating pupils, while the findings suggest that it may offer a feasible mental health prevention and early intervention approach for Northern Ireland classrooms. However, a larger definitive trial would be needed to verify the findings in this study.
\end{abstract}

\section{Keywords}

elementary school; good behaviour game; mental health; primary school; self-regulation; students behaviour; universal prevention

\section{Issue}

This article is part of the issue "Promoting Inclusion and Equality in Education" edited Allen Thurston (Queen's University Belfast, UK) and Tien-Hui Chiang (Anhui Normal University, China).

(C) 2021 by the authors; licensee Cogitatio (Lisbon, Portugal). This article is licensed under a Creative Commons Attribution 4.0 International License (CC BY).

\section{Introduction}

\subsection{Child Mental Health}

It is reported that ten to $20 \%$ of children experience mental health problems and half of all mental problems begin by the age of 14 (Kessler et al., 2005; WHO, 2018). A recent survey by the National Health Service (2017) on the mental health of children and young people in England reports that one in eight (12.8\%) of five- to 19-year-olds had at least one mental disorder when assessed in 2017. The report also details that there has been a slight increase over time in the prevalence of mental disorders, rising from $9.7 \%$ in 1999 and $10.1 \%$ in 2004 to $11.2 \%$ in 2017 . The report also notes that emotional disorders have become more common in five- to 15 -yearolds, going from $4.3 \%$ in 1999 and $3.9 \%$ in 2004 to $5.8 \%$ in 2017 (National Health Service, 2017). Children's mental health problems are frequently linked to the increased likelihood of other problems in later life, such as poor 
educational attainment, antisocial behaviour, drug and alcohol misuse and involvement in criminal activity (NICE, 2016). Mental health and behavioural problems have been identified as the primary drivers of disability and those affected are at a higher risk of attempting and completing suicide (Hawton et al., 2003; Lozano et al., 2012).

In Northern Ireland, poor mental health is the largest cause of ill health and disability, and the Public Health Agency has been keen to address this. According to the Making Life Better Report (Department of Health Northern Ireland, 2015), Northern Ireland has higher levels of mental ill health than any other region in the UK with one in five adults having a mental health condition, a 25\% higher prevalence rate than England (Department of Education Northern Ireland-DHSSPS, 2015). Recent statistics for Northern Ireland have also shown that about 45,000 young people have a mental health problem and that $>20 \%$ of young people suffer significant mental health problems by the time they reach 18 (Department of Education Northern IrelandDHSSPS, 2015). The Young Life and Times Survey conducted in Northern Ireland suggested that the mental health of young people had deteriorated between 2008 and 2013 (ARK, 2014). The mental health of children and young people in Northern Ireland has become an increasing concern for families, schools, the Department of Education Northern Ireland (DENI), and policy makers (DENI, 2017). In 2015, 318 suicides were registered in Northern Ireland, the highest figure since records began in 1970 that also indicates that suicide rates in the most deprived areas of Northern Ireland are three times higher than in the least deprived (Torney, 2016). Young people from households in more deprived areas of Northern Ireland have a $14 \%$ higher percentage risk of serious personal emotional or mental health problems than those from better off households (Schubotz, 2010).

School prevention programmes are becoming an increasingly popular means through which to address problematic behaviours, many of which are effective and show positive results (Katz et al., 2013). As reported by Wells et al. (2003) in a systematic review of universal approaches to mental health promotion in schools, the importance of developing resilience and focusing on mental health promotion in schools can help with prevention of mental health issues in later life.

\subsection{Mental Health: Prevention and Early intervention}

It is widely recognised that prevention and early intervention is a key step in addressing mental health in children and young people. In 2015, the four UK Children's Commissioners recommended to the United Nations Committee on the Rights of the Child that there should be investment in universal preventative and early intervention children's services to prevent an increase in mental health problems among children (UK Children's Commissioners, 2015). It is reported that children and young people who develop good mental health are bet- ter able to deal with emotional challenges now and in later life. They are also reported to recover more quickly from illness, and are less likely to engage in behaviours, which may put their health at risk (Chanfreau et al., 2008; Davies, 2012).

School-based prevention and early interventions are an increasingly common means through which educators, researchers, and policy makers are trying to address the issues of mental health in children and young people (Katz et al., 2013; Surgenor et al., 2016). A systematic review by Bonell et al., (2013) found that school-based interventions show the potential to improve young people's health particularly regarding violence, aggression and physical activity. Failure, however, to address problematic behaviours in childhood can have immediate and long-term effects on mental health. This may explain why many school-based interventions are designed to target problematic behaviour in the first instance, which is traditionally linked to mental health problems in adolescence and later life (Kellam et al., 2008, 2011).

Research frequently indicates positive links between self-regulation skills and pro-social behaviours (Buckner et al., 2009; Eisenberg, 2000; Hagger et al., 2009), with problematic behaviours and mental health in later life linked to children's ability to self-regulate their behaviour and emotions at a young age (Kellam et al., 2008). Research has shown, however, that $70 \%$ of young people who experience mental health problems do not have appropriate interventions at a sufficiently early age (4Children's Society, 2008). It would appear, therefore, that the classroom environment is an ideal place to address some of these issues, allowing children to acquire new skills and knowledge whilst learning to cooperate with their peers. In doing so, they may learn a range of social, emotional and behavioural skills that enable them to self-regulate, manage their thoughts, emotions and behaviours so that they can cope better with difficulties in later life (Durlak et al., 2011). One promising intervention is the PAX Good Behaviour Game (PAX GBG) on which we report here.

\section{The PAX Good Behaviour Game}

Interest in the GBG has led to a number of trials taking place within the UK and Ireland (Chan et al., 2012; Coombes et al., 2016; Humphrey et al., 2018; O'Donnell et al., 2016). Evidence from the USA, and more recently in international settings (Dijkman et al., 2015; Kellam et al., 2008; Leflot et al., 2013; Smith et al., 2018), has shown the GBG to be effective in preventing mental (cognitive), emotional and behavioural problems amongst children. The GBG was originally designed by a teacher, Muriel Saunders for her year 5 class (age 9-10) to address disruptive behaviour. This original version of the GBG was a simple invention where the pupils in a classroom were divided into teams, utilising peer competition and group rewards to reduce out-of-seat and talking-out behaviours (Barrish et al., 1969). More recent versions 
of the GBG, such as the PAX version, focus on giving children the mental ability to sustain attention, self-regulate, cooperate with others intentionally, and create peace, productivity, health and happiness for self and others (PAXis Institute, 2015).

Research from randomised trials in the USA, Belgium, and the Netherlands has shown that the PAX GBG is effective in improving a wide range of public health and educational outcomes (Dijkman et al., 2015; Kellam et al., 2008; Leflot et al., 2013; Petras et al., 2008; Poduska et al., 2008; Smith et al., 2018; Wilcox et al., 2008). Studies have also shown that the PAX GBG is effective at targeting a range of behavioural issues when implemented with pupils aged 6-12 from grade one to six (Barrish et al., 1969; Harris \& Sherman, 1973; Medland \& Stachnik, 1972). The impact of PAX GBG is highest among pupils with higher initial levels of aggression (Petras et al., 2008), and studies amongst PAX GBG pupils have shown reductions in children's (particularly boys) externalising behaviour and improvements in positive peer relations when compared with control-group children (Jiang et al., 2018). These reductions in externalising behaviour appear to be partly mediated by the improvements in peer acceptance (Witvliet et al., 2009). Overall, the GBG in all formats has shown evidence of effectiveness in preventing childhood disruptive behaviours and promoting long-term health and well-being.

There are currently two manualised versions based on the original GBG, the American Institutes of Research (AIR) GBG and the PAX GBG. The PAX version of the GBG is primarily driven by the pupils who set out the rules of their classroom. The behaviours are referred to as "PAX" and "Spleems," and use gamification and fun learning to teach pupils self-regulation, self-control, and selfmanagement in the context of collaborating with others. Things that pupils would like to happen more often in their classroom are called "PAX" (peace, productivity, health, and happiness) and things that they would like to happen less often are called "Spleems." Children quickly understand the difference between PAX behaviours and Spleems, an ability that is vital for learning sustainable self-regulation (PAXis Institute, 2015). The game is composed of a number of evidence-based "Kernels" (components or building blocks). These Kernels include games and rewards. The full details of the PAX GBG composition and rules used in this trial are published in the trial protocol (O'Keeffe et al., 2017).

\section{Theory of Change}

The theory of the intervention is illustrated in the logic model (Figure 1) by O'Keeffe et al. (2017). The primary aim of the PAX GBG is to increase self-regulation, which can lead to an improvement in behaviour, self-esteem, and peer relations. This is achieved by using rewards for good behaviour and positive reinforcement, encouraging the children to maintain attention and adhere to the classroom vision that they compiled and agreed with their teacher. The differentiating component of PAX GBG compared to other versions of the GBG is the focus on improving the self-regulation of participating pupils. Self-regulation is also referred to as selfcontrol and self-discipline (Duckworth \& Seligman, 2005), and implies an ability of the self to control or change responses in order to regulate behaviour, thoughts and emotions. Self-regulation also includes the ability to control impulses, to manage short-term desires and to make better choices by looking forward and delaying gratification (Ainslie, 1975; Mischel \& Underwood, 1974; Zimmerman, 2001).

Rather than assuming that environmental factors are the critical determinants of learning and classroom management, the programme gives ownership of the learning process to the learner. Pupils who participate in PAX GBG are guided by their own suggestions on acceptable behaviour (the PAX vision chart) in relation to what they want to see, hear, do, and feel more or less of in their classroom (PAXis Institute, 2015). Through meta-cognition and self-regulation, the PAX GBG helps pupils to think about their own behaviour and the content of the classroom vision chart that they compile together. The cognitive processes of effort and monitoring of behaviours are driven by an interest in winning the PAX game for rewards, Granny's Wacky Prizes (GWP), and receiving positive reinforcement. These are intrinsic (intangible) rewards and recognition that reinforce a sense of achievement for the pupil. By winning a GWP, the pupil reflects on their individual and collective actions according to the vision chart, which reinforces the positive behaviour (PAXis Institute, 2015; Zimmerman, 2010).

In the PAX GBG, positive reinforcement and social interdependence support and promote co-operative learning and peer relationships. The PAX GBG uses rewards for good behaviour and positive reinforcement to encourage children to work cooperatively, maintain attention and comply with the classroom vision. The classroom vision is made up of all the acceptable and unacceptable behaviours that the pupils collectively compile and agree with their teacher. This collective process is underpinned by the theory of social interdependence (Johnson \& Johnson, 2012; Johnson et al., 2010), which infers that when pupils work together cooperatively they work harder and develop positive relationships with their peers. This process helps pupils by promoting improved social and emotional wellbeing, such as mental health, self-esteem, the ability to manage stress and adversity (Johnson \& Johnson, 1999). Pupils also develop the ability to self-regulate their own behaviours and work cooperatively as part of a team in a manner that is conducive to both them and the whole team. This repeated process, in the long term, has been shown to help improve behaviour and self-esteem in participating children.

The overall aim of this study was to use a randomised controlled trial design to explore the effectiveness of the PAX GBG programme within the context of 


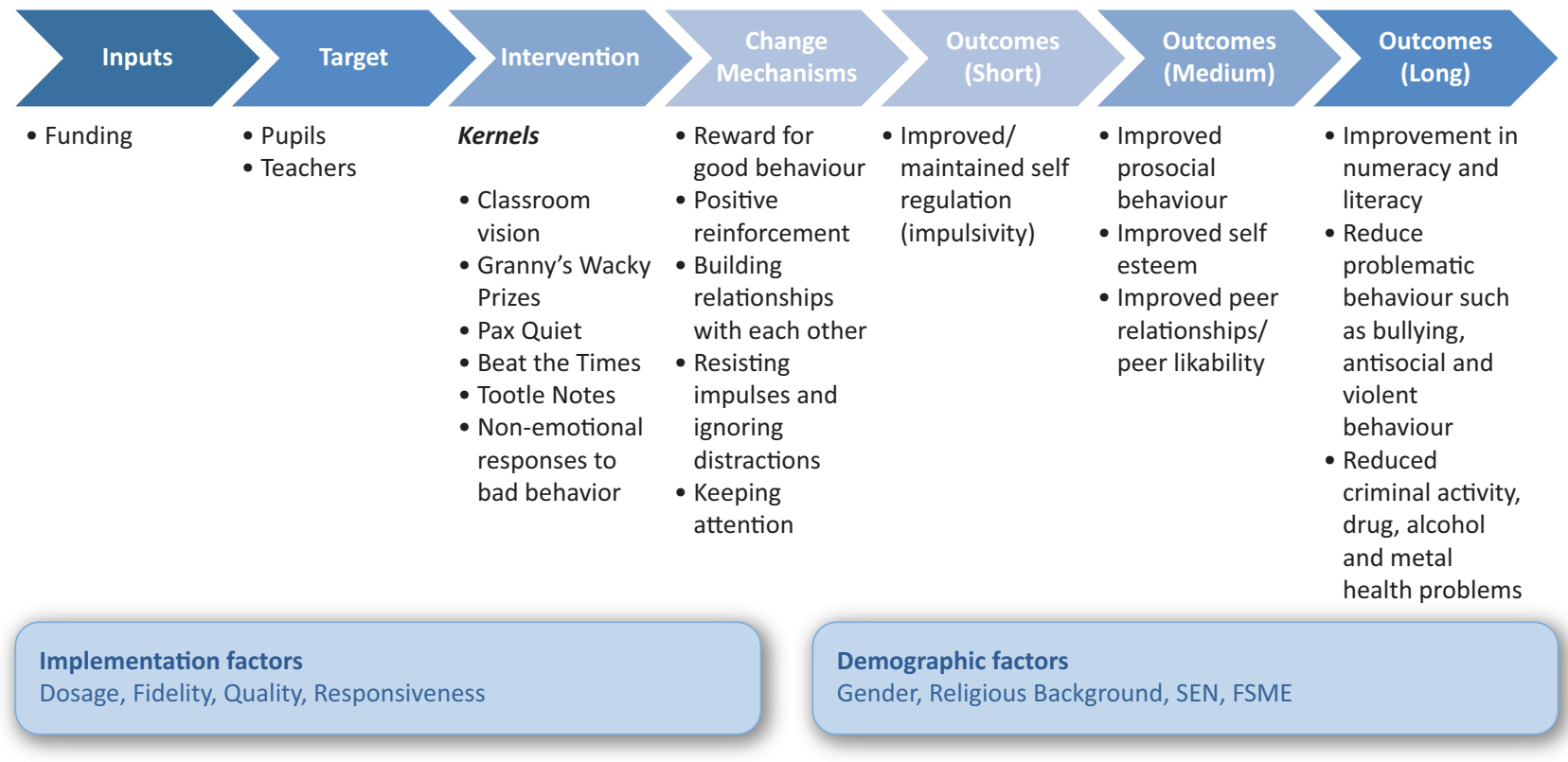

Figure 1. Logic model for the PAX GBG intervention (O'Keeffe et al., 2017).

disadvantaged schools in Northern Ireland. This article looks specifically at the outcome of self-regulation.

\section{Methods}

\subsection{Trial Design Summary}

A research protocol outlining the proposed design for this trial was collated according to the SPIRIT (2015) guidelines and is published in the International Journal of Educational Research (O'Keeffe et al., 2017). This study was designed in-line with Medical Research Council guidelines on development of complex interventions, more specifically within a Phase 2 exploratory trial (Moore et al., 2015).

The schools recruited for the exploratory trial were randomised to one of two conditions: (a) implementation of the PAX GBG for 12 weeks and (b) continue with normal classroom activity (without PAX GBG implementation). The target population was Northern Irish year 3 elementary school children (age 6-8) living in disadvantaged areas within a 10 -mile radius of Belfast city. The main aim was to measure any improvements, as a result of the intervention, on child reported self-regulation.

\subsection{Intervention}

Three of the authors of this article became PAXis Institute accredited trainers. The training was delivered by the PAXis Institute and lasted one week. The training was intensive and consisted of a mixture of theoretical and practical elements. The training covered the theoretical underpinnings, the game construct and main elements known as the Kernels and how the game works in practice. The training was led by a range of professionals, including the programme developer, Dr. Dennis Embry,
PAX partners, teachers, and staff from the PAXis institute. Teachers in the PAX GBG condition received training and were provided with a PAX GBG kit.

The training was condensed by drawing upon the key elements of the game Kernels that would be implemented as part of the trial. All the key information and instruction was extracted from the 139-page manual around the seven Kernels (PAX classroom vision, PAX language, PAX quiet, PAX game, GWP, transition games, tootle notes). A 2-day training schedule was designed and training slides were developed with sample videos of PAX GBG in action. The training had a logical sequence, taking the teachers through the programme step by step. Day one consisted of background, theory behind the programme, and all the Kernels. Day two focused on ensuring that the teacher fully understood the programme and how to implement it once they returned to the classroom. This involved practical sessions, a short test to ensure they fully understood the main concepts of the programme, and a question-and-answer session with the trainers.

The PAX GBG was played three times per day starting at 10 minutes, stretching to 40 minutes over the 12 -week period, as the children's self-regulation and behaviour improved. A classroom playing the PAX GBG typically has three to five PAX teams at any given time. The PAX GBG encourages pupils to work through the existing curriculum co-operatively and efficiently. It promotes rules of pro-social behaviour and peer concern for classmates by rewarding teams for maintaining behaviour standards (Chan et al., 2012). The teacher can generate the teams either randomly or deliberately, depending on the context of the game. The teams can be given identity in a number of ways by, for example, the use of coloured armbands, fun names or simply by seating location. The teams should be balanced to ensure that all children 
are represented as well as possible. Every team can win if it has three or fewer Spleems during a PAX GBG of a defined duration. The teacher, an adult or a designated class PAX leader can record the Spleems (PAXis Institute, 2015). A TiDier checklist table (Hoffmann et al., 2014; O'Keeffe et al., 2017) outlining all the elements of the PAX GBG programme implementation is shown in Figure A1 of the Supplementary File.

\section{Recruitment and Randomisation}

\subsection{Recruitment}

A list of elementary schools was obtained from the DENI. School selection was based on the percentage of children entitled to free school meals (FSME) defined by DENI statistics. The Belfast area was identified as having the highest percentage of elementary school children receiving FSME, $57.4 \%$ in comparison to a national average of $29.2 \%$ across the rest of Northern Ireland. The elementary schools in the sample were targeted to ensure recruitment from schools with a minimum class size of 15 , a minimum enrolment of 140 for the year group undertaking the intervention, higher than $47 \%$ FSME, and within a 10-mile radius of Belfast city centre. A total of 56 schools met the inclusion criteria and were contacted for the main trial. Nineteen schools were recruited after invitation to the trial (enrolment range between 143 to 635 and a FSME of $49.77 \%$ to $86.26 \%)$. Consent was obtained from all of the participants involved in this PAX GBG trial. Teachers and principals gave consent through consent forms issued at the recruitment stage. Consent forms were sent out by the school to the parents/guardians and consisted of an "opt out" format. This trial was approved by the Ethics Committee in the School of Social Sciences Education and Social Work at Queen's University Belfast prior to any contact with schools or pupils.

\subsection{Sample}

A total of 424 year 3 children aged between six and eight years took part in the trial. The pupils were drawn from 24 year 3 classes spread across 19 schools. Two schools dropped out before the trial began and pre-testing took place (one control school and one intervention school). Two schools dropped out after allocation to condition (one from each arm of the trial). This left a sample of 15 schools and 19 year 3 classes, with $n=355$ and these are included in the final intention to treat analysis. In the final sample there were no significant differences between the intervention and control groups on the basis of school size $(t(13)=-0.37, p=.72$ ) or FSME ( $t(13)=0.10, p=.92)$. Table 1 summarises school size, class size, and FSME of control and intervention group in the final sample. The sample, attrition and experimental processes are summarised in accordance with the CONSORT guidelines (see Figure A2 of the Supplementary File; Schulz et al., 2010).

The mean Northern Ireland Multiple Deprivation Measure (NIMDM) scores for both control and intervention were similar $\left\{M_{c}=4.50(S D=0.84)\right.$ and $M_{i}=4.54$, $(S D=0.96)\}$. The intervention and control groups were also comparable in terms of the deprivation scores of the children's place of residence (Table 2).

The breakdown of the sample by gender, special educational needs (SEN), ethnicity, English as an additional language (EAL), and the NIMDM average is summarised in Table 3. The pupil ( $n$ ) refers to the number of pupils who sat the pre- and post-test. There are notable differences between the groups in terms of the numbers dropping out prior to pretesting. Gender balance is similar in both groups. The control group had a slightly higher percentage of children from ethnicities other than white, a slightly higher percentage of children with EAL (8\%) and a slightly larger percentage of Asian (1.3\%) and other ethnicity $(1.9 \%)$ compared to the intervention.

Table 1. Sample summary.

\begin{tabular}{|c|c|c|}
\hline & Control & Intervention \\
\hline Number of Schools (N) & 7 & 8 \\
\hline \multirow[t]{2}{*}{ Number of classes (n) } & 8 & 11 \\
\hline & Mean (SD) & Mean (SD) \\
\hline School size & 320 (119) & $361(182)$ \\
\hline Class size & $21(4.66)$ & $24(2.91)$ \\
\hline FSME & $67.5(.011)$ & $61(0.09)$ \\
\hline
\end{tabular}

Table 2. Mean NIMDM.

\begin{tabular}{lcccc}
\hline & \multicolumn{2}{c}{ Control } & & Intervention \\
\cline { 2 - 3 }$n$ & Mean (standard deviation) & 162 & Mean (standard deviation) \\
\hline 242 & $4.50(0.84)$ & $4.54(0.96)$ \\
\hline
\end{tabular}


Table 3. Sample characteristics.

\begin{tabular}{|c|c|c|c|c|}
\hline \multirow{3}{*}{ Characteristic } & \multicolumn{4}{|c|}{ Group } \\
\hline & \multicolumn{2}{|c|}{ Intervention group } & \multicolumn{2}{|c|}{ Control group } \\
\hline & $n$ & $\%$ & $n$ & $\%$ \\
\hline Total number of pupils & 268 & 63.2 & 156 & 36.8 \\
\hline \multicolumn{5}{|l|}{ Gender } \\
\hline Female & 139 & 51.9 & 83 & 53.2 \\
\hline Male & 128 & 48.1 & 73 & 46.8 \\
\hline \multicolumn{5}{|l|}{ SEN } \\
\hline Yes & 86 & 32 & 44 & 27 \\
\hline No & 183 & 68 & 97 & 59.5 \\
\hline Not specified & & & 22 & 13.50 \\
\hline \multicolumn{5}{|l|}{ Ethnicity } \\
\hline White & 263 & 97.8 & 145 & 93.5 \\
\hline Mixed/multiple ethnic groups & 3 & 1.1 & 2 & 1.3 \\
\hline Asian/Asian British & 0 & 0 & 2 & 1.3 \\
\hline Black/African/Caribbean/Black British & 3 & 1.1 & 3 & 1.9 \\
\hline Other ethnic group & 0 & 0 & 3 & 1.9 \\
\hline \multicolumn{5}{|l|}{ EAL } \\
\hline Yes & 4 & 1.5 & 13 & 8 \\
\hline No & 265 & 98.5 & 150 & 92 \\
\hline
\end{tabular}

\subsection{Randomisation}

Randomisation took place at the school level. Randomisation was undertaken using both "blocking" and "minimisation" to minimize Type I error (Stolberg et al., 2004). Assignment to condition used minimisation to achieve a close balance of single/double form entry. After first rank ordering the schools in order of FSME and school size, their ranks were then block minimised to ensure an even distribution of sectors and disadvantage based on percentage FSME. They were then assigned to condition using true randomisation within these groups.

\subsection{Sample Size Calculation}

The estimation of power for the PAX GBG was provided by Optimal Design software. To detect a standardised effect size of 0.41 , with $80 \%$ power, assuming alpha 0.05 and ICC of 0.07 (and with J = 20 clusters and average class size $n=25$ ) required 500 subjects across the two arms. The effect size of +0.41 was used to model power and sample size. This effect size was used as previous effects sizes ranged from 0.12 to 0.57 (O'Donnell et al., 2016) and 0.56 to 0.83 (Ghaderi et al., 2017) for measures of pupil behaviours. A conservative estimate of 0.41 appeared to be reasonable to ensure analyses were not left underpowered. The ICC is in line with similar programmes such as Family Skills (Hussain et al., 2017), which have shown ICCs of between 0.02 and 0.15 . The calculation also allows for a $5 \%$ attrition level at the individual or cluster level, and still being able to detect an effect size of +0.41 .

\subsection{Measures}

The primary outcome of the trial was self-regulation, which corresponds to the logic model of the programme (O'Keeffe et al., 2017). The primary outcome measure chosen was the child self-control rating scale (Rorhbeck et al., 1991), which was selected on the basis that it was relatively short, well-validated, and designed to assess how well children self-regulate. The 33-item scale was modelled on the teacher and parent self-control rating scale (Kendall \& Wilcox, 1979), and previous studies have indicated good reliability with a Cronbach's Alpha $(\alpha=0.9)$. It uses a 5-point Likert scale, which ranges from not at all like me to a lot like me. The questionnaires were compiled online using a custom design that was user friendly for young children and the data collection was collected using iPads, with this method tested in a small feasibility study prior to commencing this exploratory trial. All pupils in both the intervention and control groups were tested in their classroom one week prior to teacher training and were tested again just one week after the intervention finished. The children gave their consent for participation before data collection began.

\subsection{Implementation Fidelity}

A thorough process evaluation was conducted for this exploratory trial to measure the fidelity of delivery and acceptability of the programme, following the Medical Research Council framework (Moore et al., 2015) and the relevant CONSORT statement (Moher et al., 2001). More 
details of the process evaluation plan are available in the trial protocol (O'Keeffe et al., 2017).

\section{Analysis}

The statistical analysis was guided by the intervention logic model, as previously outlined in the trial protocol, (O'Keeffe et al., 2017). Data were captured via Lime Survey and transferred to STATA 15 . The raw data were anonymised using an assigned unique ID. Internal reliability was assessed using Cronbach's alpha $(\alpha=0.92)$, which is in line with that found in previous studies. The main analysis was based on complete cases (children deleted from analysis if they had missing pre or post-test scores). The missing data per variable lay between 0.6 and $26.8 \%$. In subsidiary analysis, as per Rubin's (1976) framework, we assumed data to be missing at random, and used Multiple Imputation by Chained Equations (MICE) to conduct a sensitivity analysis. The NIMDM (NISRA, 2015) was calculated using each child's postcode via the Northern Ireland Statistics and Research Agency area profiles. The measure is ranked from 1 (most deprived) to 5022 (least deprived).

Descriptive statistics \{means (SD); medians (IQR)\} were generated for each outcome and any changes in the intervention group receiving the 12-week GBG programme was compared to the control group using preand post-test measures. Initial effects of the PAX GBG implementation on the outcomes were analysed on an-intention-to-treat basis. We also examined the effect of clustering on the outcomes.

The difference between mean scores for the intervention and control were tested using hierarchical linear modelling (HLM). HLM was used to account for clustering effects in the data. The main effects of clustering were determined to be at the school level and so two-level model was used to take account of clustering. HLM used the post-test score (dependent variable) with group assignment and the related pre-test scores as independent variables. HLM analysis was also used to control for in the data. The effect sizes (Cohen's $d$ ) were calculated using the Campbell effect size calculator (Wilson, n.d.) using the standardised mean difference, the unstandardised regression coefficient (B) from intervention group and the standard deviation (SD) of the pretest whole group.

\section{Results}

\subsection{Intervention Effects on Self-Regulation}

An independent sample t-test based on complete cases was used for initial exploration of pre- to post-test change in each of the means of the primary outcome scales. This analysis was exploratory on the main outcome only, and a fuller analysis of data taking account of interaction of variables follows. The results provided some evidence of effectiveness through maintenance of self-regulation during the 12-week period, in that there was a decline in self-regulation in the control group and no change in the intervention group, as shown in Table 4.

In an HLM model (Tables 5, 6, and 7), the adjusted post-test to pre-test differences were compared between the control and intervention groups controlling for clustering on the self-regulation outcomes within schools. The developed model is presented across these tables showing how school (cluster) and individual effects were taken into account in the final models presented in Table 8.

After determining that there was a clustering effect to explore, HLM was undertaken, with and without multiple imputation, to assess the effects of missing data on outcomes. The effect sizes of the resultant model are presented both with, and without, multiple imputation for missing data in Table 6. The observed data model ( $\beta=.2,95 \% \mathrm{Cl} .206$ to $.642 ; d=.42)$ and the model

Table 4. $T$ test.

\begin{tabular}{lllllllll}
\hline Outcome & Control or Intervention & $\mathrm{N}$ & Mean & $\mathrm{SD}$ & $\mathrm{SE}$ & $\mathrm{t}$ & $\mathrm{df}$ & Sig. \\
\hline Pre test self-regulation & Intervention & 224 & 4.02 & 0.713 & 0.048 & 3.05 & 256.333 & 0.003 \\
& Control & 131 & 3.76 & 0.768 & 0.067 & & & \\
\cline { 2 - 7 } Post test self-regulation & Intervention & 224 & 4.02 & 0.673 & 0.045 & 3.94 & 233.017 & $<.001$ \\
& Control & 131 & 3.69 & 0.814 & 0.071 & & & \\
\hline
\end{tabular}

Table 5. HLM model of self-regulation.

\begin{tabular}{lrrrl}
\hline Source & SS & df & MS & Number of observations $=355$ \\
\hline Model & 58.17 & 2 & 29.08 & \\
Residual & 137.95 & 352 & 0.39 & Prof $>\mathrm{F}>0.0001$ \\
Total & 196.12 & 354 & 0.55 & R-squared $=0.30$ \\
& & & Adjusted R-squared $=0.29$ \\
& & & Root MSE $=0.626$ \\
\hline
\end{tabular}


Table 6. HLM main effects model for pre-post changes test on self-regulation.

\begin{tabular}{llcrrrr}
\hline Post-self-regulation & Coef. & Standard error & $t$ & $\mathrm{P}>\mathrm{t}$ & \multicolumn{1}{c}{$95 \% \mathrm{Cl}$} \\
\hline Main effects & 0.20 & 0.07 & 2.93 & 0.004 & 0.07 & 0.34 \\
Pre-self-regulation & 0.51 & 0.05 & 11.19 & $>0.001$ & 0.42 & 0.60 \\
Constant & 1.178 & 0.18 & 9.90 & $>0.001$ & 1.42 & 2.13 \\
\hline
\end{tabular}

Table 7. ANOVA showing between school clustering effects on self-regulation.

\begin{tabular}{lccccc}
\hline Source & SS & df & MS & F & Prob $>$ F \\
\hline Between school & 22.04 & 14 & 1,57 & 2.95 & 0.0003 \\
Within school & 193.17 & 362 & 0.53 & & \\
Total & 215,21 & 376 & 0.57 & &
\end{tabular}

Estimated SD of school effects $=0.20$

Estimated SD individual effects $=0.73$

generated with multiply imputed data $(\beta=.2,95 \% \mathrm{Cl} .009$ to $.40 ; d=.42$ ), both indicate that self-regulation may have improved as a result of the intervention. The similarity in the outcomes and effects sizes from the observed and imputed models, indicated that missing data was not having a substantive effect on findings.

The ICC for this sample is 0.01 , which is considered low in comparison to similar programmes such as Roots of Empathy (Connolly et al., 2018). An ICC of less than 0.40 indicates poor intra-class correlation (how strongly units in the same group resemble each other; see Cicchetti, 1994).

\section{Discussion}

In summary, this exploratory trial provided some evidence that the PAX GBG helped improve self-regulation in participating pupils. This trial is, to date, the only randomized controlled trial (RCT) of the PAX GBG to be conducted in Northern Ireland and Ireland. Although a recent large scale RCT took place in the UK of the AIR version of the GBG, it measured mainly reading improvement and behaviour. This trial looked specifically at the PAX GBG, which uses age specific, non-material, fun rewards that are cost effective and sustainable in the long-term. The PAX version of the GBG claims to go beyond the traditional conceptions of behaviour modification, with the main outcome of improved self-regulation.

Informed by the logic model outlined by O'Keeffe et al. (2017), this trial was designed to explore the effect of the PAX GBG at post-test and at the end of the programme on the primary outcome of self-regulation. A number of secondary outcomes including cooperative learning, self-esteem and behaviour were also assessed but are not reported in this article. The trial also explored whether the PAX GBG had a differential impact on pupils depending on their gender and their EAL, SEN, and socioeconomic status.

The use of the pupil driven PAX vision chart may have encouraged the pupils to think about their own behaviours in the classroom through meta-cognition. The PAX GBG encouraged pupils to reinforce each other for group success in the game, driven by an interest in winning the PAX game rewards (GWPs) and receiving positive reinforcement. Pupils interact together and, in doing so, improve social skills and competencies and promote each other's success (Johnson et al., 2010; Roseth et al., 2008). This in turn would have enhanced their sense of self-satisfaction and motivation to continue to improve and regulate their behaviour (PAXis Institute, 2015; Zimmerman, 2010). The improvement in self-regulation may be attributed to the start-stop cognitive processes or the intrinsically reinforcing GWPs. The rewards for individual and collective efforts may have encouraged the pupils' desire to learn more selfregulation (Embry, 2016; PAXis Institute, 2015). The fun factor may also have contributed to the detected improvement in self-regulation; the quirky elements of these Kernels, such as the GWPs, PAX quiet, and Beat the Timer, are considered to be the key elements in

Table 8. Summary of effect sizes on observed and MI data (cluster control).

\begin{tabular}{|c|c|c|c|c|c|c|c|c|c|c|c|c|}
\hline \multirow[t]{4}{*}{ Outcome } & \multirow{2}{*}{\multicolumn{2}{|c|}{ Sample size }} & \multicolumn{5}{|c|}{ Observed } & \multicolumn{5}{|c|}{ MI } \\
\hline & & & $\beta$ & $p$ & $\mathrm{Cl}$ & $\mathrm{Cl}$ & $d$ & $\beta$ & $p$ & $\mathrm{Cl}$ & $\mathrm{Cl}$ & $d$ \\
\hline & & & Regression & & & & & egressior & & & & \\
\hline & Intervention & Control & Co-Eff & & & & ES & Co-Eff & & & & ES \\
\hline Self-regulation & 224 & 131 & 0.20 & 0.04 & 0.206 & 0.642 & 0.42 & 0.20 & 0.04 & 0.009 & 0.40 & 0.42 \\
\hline
\end{tabular}


this programme (Embry, 2004; Embry \& Biglan, 2008). The evidence-based Kernels in the PAX GBG may have driven the change mechanisms as shown previously in Figure 1. The effect size detected for self-regulation may also be explained by the team-working and cooperative learning element of the PAX GBG. As noted previously, pupils have the opportunity to play and cooperate with their peers whilst practicing goal-directed behaviour, all of which are fundamental to the development of selfregulation (Vohs \& Baumeister, 2011; Vygotsky, 1978).

The findings from this trial are reflective of those outlined in a recent systematic review and meta-analysis of 49 randomised clinical trials, evaluating 50 selfregulation interventions (Pandey et al., 2018) which concluded that interventions such as the PAX GBG are effective in children and young people. Academic achievement, mental health, behavioural improvements are reported as some of the main outcomes of selfregulation interventions.

It is worth noting that in an exploratory analysis, there was some evidence that gender, SEN, EAL and socio-economic status predicted post-test score for selfregulation when accounting for pre-test score. However, given the small sample size and small numbers within these subgroups, the interaction effects must be treated with caution. In addition, given the large number of tests undertaken in relation to exploring interaction effects, this may have increased the likelihood of a type I error (false positive). The findings are only exploratory, with the aim of identifying any patterns of interest that may be useful to consider in a larger phase 3 definitive trial.

The findings of this exploratory trial of the PAX GBG in Northern Ireland appear to have met the success criteria by partially supporting the first (proximal) step in the logic model, that is, the improvement of self-regulation in the short term compared to those in the control group. This may serve as a promising indication for subsequent steps for a phase 3 definitive trial.

\section{Limitations}

There were a number of limitations to this study, the first of which is that the researcher in this trial was also the trainer and evaluator. This may have introduced some unconscious bias into the study. Ideally, if a future phase 3 definitive trial was to be conducted then these responsibilities should be separated.

Missing data were also an issue and the reason for missing data was due to some of the teachers not filling in the pre-test questionnaires on time. The post-test child questionnaires were completed in the last two weeks of June and some children were absent from the classroom. Teachers noted that some families were taking holidays before the peak holiday period, which would explain some of the missing data from children at posttest. To overcome this, MICE was used for imputation and analysis was conducted on both imputed and observed sets. In future studies, consideration should be given to the time of year when testing in the classroom, as this would help avoid the times when pupils are more likely to be absent. In addition, a future trial of the PAX GBG would benefit from recruiting a larger number of schools, with over recruitment to allow for attrition.

A key limitation is that the trial only lasted 12 weeks between pre- and post-test, which is a very short time to fully implement such a substantial programme. As per the logic model, the evidence-based Kernels of the game aimed to develop pupils' ability to self-regulate their behaviours and work as part of a team. It was suggested that this repeated process, in time, would help improve behaviour and self-esteem in participating pupils. Future studies of the PAX GBG would benefit from a longer implementation period of two years such as that in the AIR GBG study by Humphrey et al. (2018).

\section{Conclusion}

This exploratory RCT assessed the PAX GBG as a potential early intervention for children in Northern Ireland classrooms to prevent mental ill health, in particular among those living in areas of high socio-economic disadvantage. The main aim of this study was to explore the effect of the PAX GBG on self-regulation among year 3 elementary school children. The study used a cluster randomised controlled trial design with a total of 15 schools (19 classes) randomised to intervention and control. The main aim of the data analysis was to explore the effect of the PAX GBG on the outcomes and produce an estimate of an effect size for a larger phase 3 definitive trial.

The PAX GBG did show promise and actually improved the first step (proximal) outcome (selfregulation) in the theory of change model for participating pupils. This study looked primarily at the short-term effect of the PAX GBG. However, there is a recognised link between self-regulation and mental health in later life. The ability to strengthen self-regulation may also be important for longer-term outcomes such as suicide prevention in later life (Brüdern et al., 2016; Gottfredson \& Hirschi, 1990).

Many of the GBG studies have originated in the USA and have focused mainly on children's aggressive behaviour at school and were conducted with pupils from low income, urban areas that were predominantly African American. In contrast the studies in Europe with Dutch and Belgian children took place with predominately children from middle- to high-socio-economic backgrounds. However, it would appear that previously reported gains in these studies can be replicated in high poverty schools in Northern Ireland (Dijkman et al., 2015; Leflot et al., 2013; Werthamer-Larsson et al., 1991).

A larger scale trial would be beneficial to further investigate the modest effects that emerged from this trial and, indeed, to further explore the medium-term outcomes of the theoretical model as outlined by O'Keeffe et al. (2017). It is hoped that the findings in 
this study will contribute to the existing literature on the PAX GBG and offer a basis on which to conduct a phase 3 definitive trial of the PAX GBG in Northern Ireland. In doing so, it may make a positive contribution to the health and wellbeing of children and young people by helping to improve self-regulation in the short term, and mental health in later life.

\section{Acknowledgments}

The authors would like to express their gratitude to the following people and institutions: The PAXis Institute, Dr Dennis Embry, The Public Health Agency Northern Ireland, and Queen's University Belfast. The trial was part of a PhD study funded by the Department of Education in Northern Ireland and a contribution of $£ 30,000$ from the Public Health Agency Northern Ireland. Consent was obtained from all of the participants involved in this PAX GBG trial. Teachers and principals gave consent through consent forms issued at the recruitment stage. This trial was approved by the Ethics Committee of the School of Social Sciences Education and Social Work, Queen's University Belfast, prior to any contact with schools or pupils.

\section{Conflict of Interests}

The authors declare that they have no conflict of interests.

\section{Supplementary Material}

Supplementary material for this article is available online in the format provided by the author (unedited).

\section{References}

4Children's Society. (2008). The good childhood inquiry: Health research evidence. Children's Society

Ainslie, G. (1975). Specious reward: A behavioural theory of impulsiveness and impulse control. Psychological Bulletin, 82(4). https://psycnet.apa.org/doi/ $10.1037 /$ h0076860

ARK. (2014). Young Life and Times Survey. https://www. ark.ac.uk/ylt

Barrish, H. H., Saunders, M., \& Wolf, M. M. (1969). Good behavior game: Effects of individual contingencies for group consequences on disruptive behavior in a classroom. Journal of Applied Behavior Analysis, 2(2). 119-124.

Bonell, C., Wells, H., Harden, A., Jamal, F., Fletcher, A., Thomas, J., Campbell, R., Petticrew, M., Whitehead, M., Murphy, S., \& Moore, L. (2013). The effects on student health of interventions modifying the school environment: Systematic review. Epidemiology Community Health, 67(8), 677-681.

Brüdern, J., Berger, T., Caspar, F., Maillart, A. G., \& Michel, K. (2016). The role of self-organization in the suicidal process. Psychological Reports, 118(2), 668-685.

Buckner, J. C., Mezzacappa, E., \& Beardslee, W. R. (2009). Self-regulation and its relations to adaptive functioning in low income youths. The American Journal of Orthopsychiatry, 79(1), 19-30.

Chan, G., Foxcroft, D., Coombes, L., \& Allen, D. (2012). Improving child behaviour management: An evaluation of the Good Behaviour Game in UK primary schools. Oxford Brookes University. http://www. swph.brookes.ac.uk/images/pdfs/research/GBG_ UK_Final_Evaluation_Report

Chanfreau, J., Lloyd, C., Byron, C., Roberts, C., Craig, R., De Feo, D., \& McManus, S. (2008). Predicting wellbeing. NatCen Social Research.

Cicchetti, D. V. (1994). Guidelines, criteria, and rules of thumb for evaluating normed and standardized assessment instruments in psychology. Psychological Assessment, 6(4), 284-290.

Connolly, P., Miller, S., Kee, F., Sloan, S., Gildea, A., Mclntosh, E., \& Bland, J. M. (2018). A cluster randomised controlled trial and evaluation and cost-effectiveness analysis of the Roots of Empathy schools-based programme for improving social and emotional wellbeing outcomes among 8- to 9-year-olds in Northern Ireland. Public Health Research.

Coombes, L., Chan, G., Allen, D., \& Foxcroft, D. R. (2016). Mixed-methods evaluation of the Good Behaviour Game in English primary schools. Journal of Community \& Applied Social Psychology, 26(5). https://doi. org/10.1002/casp.2268

Davies, D. S. C. (2012). Chief medical officer annual report 2012: Children and young people's health. Department of Health and Social Care. https://www. gov.uk/government/publications/chief-medicalofficers-annual-report-2012-our-children-deservebetter-prevention-pays

Department of Education Northern Ireland-DHSSPS. (2015). Promoting and sustaining good behaviourDiscipline strategy for schools. https://www. education-ni.gov.uk/publications/circular-199825promoting-and-sustaining-good-behaviour-schools

Department of Education Northern Ireland. (2017). Children and young people's strategy 2017-2027. https://www.education-ni.gov.uk/consultations/ children-and-young-peoples---strategy-2017-2027

Department of Health Northern Ireland. (2015). Making life better: $A$ whole system framework for public health (2013-23). https://www.health-ni.gov.uk/ topics/health-policy/making-life-better

Dijkman, M. A. M., Harting, J., \& Van, D. W. (2015). Adoption of the Good Behaviour Game: An evidencebased intervention for the prevention of behaviour problems. Health Education Journal, 74(2), 168-182.

Duckworth, A. L., \& Seligman, M. E. (2005). Self-discipline outdoes IQ in predicting academic performance of adolescents. Psychological Science, 16(12), 939-944. Durlak, J. A., Weissberg R. P., Dymnicki A. B., Taylor 
R. D., \& Schellinger, K. B. (2011). The impact of enhancing students' social and emotional learning: a meta-analysis of school-based universal interventions. Child Development, 82(1), 405-432.

Eisenberg, N. (2000). Emotion, regulation, and moral development. Annual Review of Psychology, 51(1), 665-697.

Embry, D. D. (2004). Community-based prevention using simple, low-cost, evidence-based kernels and behavior vaccines. Journal of Community Psychology, 32(5). https://doi.org/10.1002/jcop.20020

Embry, D. D. (2016). The Good Behavior Game. The PAXIS Institute. https://paxis.org/news/view/spleems-paxand-wacky-prizes

Embry, D. D., \& Biglan, A. (2008). Evidence-based Kernels: Fundamental units of behavioral influence. Clinical Child and Family Psychology Review, 11(3), 75-113.

Ghaderi, A., Johansson, M., \& Enebrink, P. (2017). Pilotstudie av PAX i skolan: En kulturanpassad version av PAX Good Behavior Game [A pilot study of PAX in school: A culturally adapted version of the PAX Good Behavior Game]. Karolinska Institute. https:// www.folkhalsomyndigheten.se/contentassets/ 15e7ae8c391e420ca89690c0afff1eaa/pax-goodbahavior-game-pilotstudie.pdf

Gottfredson, M. R., \& Hirschi, T. (1990). A general theory of crime. Stanford University Press.

Hagger, M. S., Wood, C., Stiff, C., \& Chatzisarantis, N. L. D. (2009). The strength model of self-regulation failure and health-related behaviour. Health Psychology Review, 3(2), 208-238.

Harris, V. W., \& Sherman, J. A. (1973). Use and analysis of the "Good Behavior Game" to reduce disruptive classroom behavior. Journal of Applied Behavior Analysis, 6(3), 405-417.

Hawton, K., Houston, K., Haw, C., Townsend, E., \& Harriss, L. (2003). Comorbidity of axis I and axis II disorders in patients who attempted suicide. The American Journal of Psychiatry, 160(8), 1494-1500.

Hoffmann, T. C., Glasziou, P. P., Boutron, I., Milne, R., Perera, R., Moher, D., Altman, D. G., Barbour, V., Macdonald, H., Johnston, M., \& Lamb, S. E. (2014). Better reporting of interventions: Template for intervention description and replication (TIDieR) checklist and guide. The BMJ, 348. https://doi.org/10.1136/ bmj.g1687

Humphrey, N., Hennessey, A., Ashworth, E., Wo, L., Frearson, K., Petersen, K., Panayiotou, M., Lendrum, A., Wigelsworth, M., Birchinall, E., Squires, G., \& Pampaka, M. (2018). Good Behaviour Game evaluation report and executive summary. Education Endowment Foundation.

Hussain, F., Wishart, R., Marshall, L., Frankenberg, S., Bussard, L., Chidley, S., Hudson, R., Votjkova, M., \& Morris, S. (2017). Family skills evaluation report. Education Endowment Foundation. https://education endowmentfoundation.org.uk/projects-andevaluation/projects/family-skills
Jiang, D., Santos, R., Josephson, W., Mayer, T., \& Boyd, L. (2018). A comparison of variable-and person-oriented approaches in evaluating a universal preventive intervention. Prevention Science, 19(6), 738-747.

Johnson, D. W., \& Johnson, R. T. (1999). Making cooperative learning work. Theory into Practice, 38(2), 67-73.

Johnson, D. W., \& Johnson, R. T. (2012). Restorative justice in the classroom: Necessary roles of cooperative context, constructive conflict, and civic values. Negotiation and Conflict Management Research, 5(1), 4-28.

Johnson, D. W., Johnson, R. T., \& Roseth, C. (2010). Cooperative learning in middle schools: Interrelationship of relationships and achievement. Middle Grades Research Journal, 5(1), 1-18.

Katz, C., Bolton, S., Katz, L. Y., Isaak, C., Tilston-Jones, T., \& Sareen, J. (2013). A systematic review of schoolbased suicide prevention programs. Depression and Anxiety, 30(10), 1030-1045.

Kellam, S. G., Brown, C. H., Poduska, J. M., lalongo, N. S., Wang, W., Toyinbo, P., Petras, H., Ford, C., Windham, A., \& Wilcox, H. C. (2008). Effects of a universal classroom behavior management program in first and second grades on young adult behavioral, psychiatric, and social outcomes. Drug and Alcohol Dependence, 95, 5-28.

Kellam, S. G., Mackenzie, A. C. L., Brown, C. H., Poduska, J. M., Wang, W., Petras, H., \& Wilcox, H. C. (2011). The Good Behavior Game and the future of prevention and treatment. Addiction Science and Clinical Practice, 6(1), 1030-1045.

Kendall, P. C., \& Wilcox, L. E. (1979). Self-control in children: Development of a rating scale. Journal of Consulting and Clinical psychology, 47(6), 1020-1029.

Kessler, R. C., Berglund, P., Demler, O., Jin, R., Merikangas, K. R., \& Walters, E. E. (2005). Lifetime prevalence and age-of-onset distributions of DSM-IV disorders in the national comorbidity survey replication. Archives of General Psychiatry, 62(6), 593-602.

Leflot, G., Van Lier, P. A. C., Onghena, P., \& Colpin, H. (2013). The role of children's on-task behavior in the prevention of aggressive behavior development and peer rejection: A randomized controlled study of the Good Behavior Game in Belgian elementary classrooms. Journal of School Psychology, 51, 187-199.

Lozano, R., Naghavi, M., Foreman, K., Lim, S., Shibuya, K., Aboyans, V., \& Remuzzi, G. (2012). Global and regional mortality from 235 causes of death for 20 age groups in 1990 and 2010. A systematic analysis for the global burden of disease study 2010. The Lancet, 380(9859), 2095-2128.

Medland, M. B., \& Stachnik, T. J. (1972). Good Behavior Game: A replication and systematic analysis. Journal of Applied Behavior Analysis, 5(1), 45-51.

Mischel, W., \& Underwood, B. (1974). Instrumental ideation in delay of gratification. Child Development, 25(4), 1083-1088. 
Moher, D., Jones, A., Lepage, L., \& Group, F. T. C. (2001). Use of the CONSORT statement and quality of reports of randomized trials: A comparative before-and-after evaluation. JAMA: Journal of the American Medical Association, 285(15), 1992-1995.

Moore, G. F., Audrey, S., Barker, M., Bond, L., Bonell, C., Hardeman, W., Moore, L., O'Cathain, A., Tinati, T., Wight, D., \& Baird, J. (2015). Process evaluation of complex interventions: Medical Research Council guidance. The BMJ, 350. https://doi.org/10.1136/ bmj.h1258

National Health Service. (2017). Mental health of children and young people in England, 2020: Wave 1 follow up to the 2017 survey. https://digital.nhs.uk/ data-and-information/publications/statistical/ mental-health-of-children-and-young-people-inengland/2020-wave-1-follow-up

NICE. (2016). Quality standard QS128 early years: Promoting health and wellbeing in under 5s. https:// www.nice.org.uk/guidance/qs128

NISRA. (2015). Northern Ireland multiple deprivation measure 2010. https://www.nisra.gov.uk/statistics/ deprivation

O’Donnell, M., Morgan, M., Embry, D. E., Kelly, N., \& Owens, C. (2016). Supporting the development of pupils' self-regulation skills: Evaluation of the PAX GBG Programme in Ireland. Irish Teachers' Journal, $4(1), 9-29$.

O'Keeffe, J., Thurston, A., Kee, F., O’Hare, L., \& Lloyd, K. (2017). Protocol: A feasibility study and a pilot cluster randomised controlled trial of the PAX 'Good Behaviour Game' in disadvantaged schools. International Journal of Educational Research, 86, 78-86.

Pandey, A., Hale, D., Das, S., Goddings, A. L., Blakemore, S. J., \& Viner, R. M. (2018). Effectiveness of universal self-regulation-based interventions in children and adolescents: A systematic review and meta-analysis. JAMA Pediatrics, 172(6), 566-575.

PAXis Institute. (2015). PAX Good Behaviour Game. https://www.paxis.org/pax-good-behavior-game/

Petras, H., Kellam, S. G., Brown, C. H., Muthén, B. O., lalongo, N. S., \& Poduska, J. M. (2008). Developmental epidemiological courses leading to antisocial personality disorder and violent and criminal behavior: Effects by young adulthood of a universal preventive intervention in first-and second-grade classrooms. Drug and Alcohol Dependence, 95, S45-S59.

Poduska, J. M., Kellam, S. G., Wang, W., Brown, C. H., Ialongo, N. S., \& Toyinbo, P. (2008). Impact of the Good Behavior Game, a universal classroom-based behavior intervention, on young adult service use for problems with emotions, behavior, or drugs or alcohol. Drug and Alcohol Dependence, 95, S29-S44.

Rorhbeck, C. A., Azar, S. T., \& Wagner, P. E. (1991). Child self-control rating scale: Validation of a child selfreport measure. Journal of Clinical Child and Adolescent Psychology, 20(2), 179-183.
Roseth, C. J., Johnson, D. W., \& Johnson, R. T. (2008). Promoting early adolescents' achievement and peer relationships: The effects of cooperative, competitive, and individualistic goal structures. Psychological Bulletin, 134, 223-246.

Rubin, D. B. (1976). Inference and missing data. Biometrika, 63(3), 581-592.

Schubotz, D. (2010). The mental and emotional health of 16-year-olds in Northern Ireland. Evidence from the Young Life and Times Survey. A report for the Patient and Client Council. Young Life and Times. http:// www.ark.ac.uk/ylt/results/PCC_YLT_mental_ health_report.pdf

Schulz, K. F., Altman, D. G., \& Moher, D. (2010). CONSORT 2010 statement: Updated guidelines for reporting parallel group randomized trials. Annals of Internal Medicine, 152(11), 726-732.

Smith, E. P., Osgood, D. W., Oh, Y., \& Caldwell, L. C. (2018). Promoting afterschool quality and positive youth development: Cluster randomized trial of the PAX Good Behavior Game. Prevention Science, 19(2), 159-173.

SPIRIT. (2015). SPIRIT guidelines. http://www.spiritstatement.org/spirit-statement

Stolberg, H. O., Norman, G., \& Trop, I. (2004). Randomized controlled trials. American Journal of Roentgenology, 183(6), 1539-1544.

Surgenor, P. W. G., Quinn, P., \& Hughes, C. (2016). Ten recommendations for effective school-based, adolescent, suicide prevention programs. School Mental Health, 8(4), 413-424.

Torney, K. (2016, July 29). Suicide rates in Northern Ireland highest on record. The Detail. https:// thedetail.tv/articles/suicide-deaths-in-northernireland-highest-on-record

UK Children's Commissioners. (2015). Report of the UK Children's Commissioners: The UN Committee on the Rights of the Child examination of the fifth periodic report of the United Kingdom of Great Britain and Northern Ireland. Children and Young People's Commissioner Scotland. https://cypcs.org.uk/resources/ fifth-uk-periodic-report

Vohs, K. D., \& Baumeister, R. F. (Eds.). (2011). Handbook of self-regulation: Research, theory, and applications (2nd ed.). Guilford Press.

Vygotsky, L. (1978). Interaction between learning and development. Readings on the Development of Children, 23(3), 34-41.

Wells, J., Barlow, J., \& Stewart-Brown, S. (2003). A systematic review of universal approaches to mental health promotion in schools. Health Education, 103(4), 197-220.

Werthamer-Larsson, L., Kellam, S., \& Wheeler, L. (1991). Effect of first-grade classroom environment on shy behaviour, aggressive behaviour, and concentration problems. American Journal of Community Psychology, 19(4), 585-602.

WHO. (2018). Mental health action plan (2013-2020). 
https://www.who.int/mental_health/publications/ action_plan/en

Wilcox, H. C., Kellam, S. G., Brown, C. H., Poduska, J. M., Ialongo, N. S., Wang, W., \& Anthony, J. C. (2008). The impact of two universal randomized first- and secondgrade classroom interventions on young adult suicide Ideation and attempts. Drug and Alcohol Dependence, 95, S60-S73.

Wilson, D. B. (n.d.). Practical meta-analysis effect size calculator [Online calculator]. https://campbell collaboration.org/research-resources/effect-sizecalculator.html

Witvliet, M., Van Lier, P. A. C., Cuijpers, P., \& Koot, H.
M. (2009). Testing links between childhood positive peer relations and externalizing outcomes through a randomized controlled intervention study. Journal of Consulting and Clinical Psychology, 77(5), 905-915.

Zimmerman, B. J. (2001). Theories of self-regulated learning and academic achievement: An overview and analysis. In B. J. Zimmerman \& D. H. Schunk (Eds.), Self-regulated learning and academic achievement: Theoretical perspectives (pp. 1-65). Routledge.

Zimmerman, B. J. (2010). Becoming a self-regulated learner: An overview. Theory into Practice, 41(2), 64-70.

\section{About the Authors}

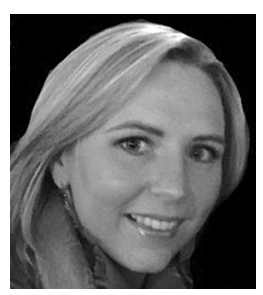

Joanne O'Keeffe (PhD) is a post-doctoral researcher in the School of Social Sciences, Education and Social Work at Queen's University Belfast. She is particularly interested in research with children and young people in the area of academic attainment, health and wellbeing, in particular those children and young people from socio-economic disadvantaged backgrounds. Her work mainly involves using randomised controlled trial methodologies and evidence based programme evaluation in education. She currently supports the university's Widening Participation Unit (WPU) on suitable evaluation strategies of outreach delivery.

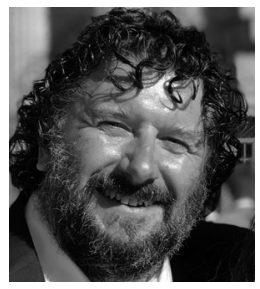

Allen Thurston holds research interests in undertaking experimental research design for educational trials and trials of health initiatives in schools. Theoretically, his work focusses on pedagogical perspectives surrounding using cooperative learning, peer tutoring and improving literacy for students living in high poverty communities aged 3-18 (including current projects in Colombia, Chile, Lesotho, and South Africa). He is the editor-in-chief of the International Journal of Educational Research (IJER) and is on the editorial board of Technology, Pedagogy and Education and Educational Psychology.

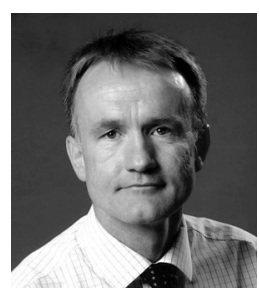

Frank Kee is the director of the Centre for Public Health in the School of Medicine, Dentistry and Biomedical Sciences, and previously directed one of the UKCRC Centres of Excellence for Public Health Research (2008-2018). Professor Kee's interests span a wide range of subjects in epidemiology, public health, health services research and complexity science, and in finding better ways to evaluate the impact of our academic endeavours, both methodologically and in terms of knowledge mobilisation that can impact policy and practice.

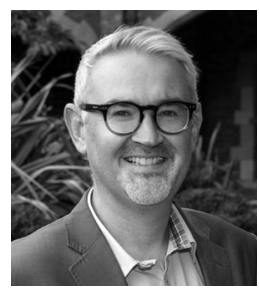

Liam O'Hare (PhD) holds research interests in the area of social and educational innovation. Generally, his work explores the design, implementation, and evaluation of intervention programmes and supports, which aim to improve population level outcomes such as educational achievement, social behaviour, and wellbeing. He has a particular focus on improving outcomes for children and young people in disadvantaged schools or communities. His methodological expertise lies in the prevention and early intervention methods such as logic modelling, participatory co-design, implementation science, psychometrics, and randomised controlled trials.

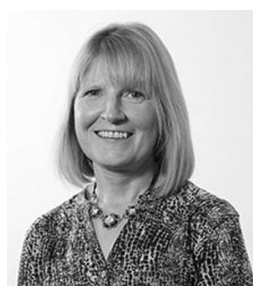

Katrina Lloyd (PhD) is a lecturer in the School of Social Sciences, Education and Social Work at Queen's University Belfast. Her main research interest is in children's mental health and wellbeing, and she developed-and runs annually-an online survey of 10 and 11-year-old children in Northern Ireland, the Kids' Life and Times. 